Review

\title{
Solid State Hydrogen Storage in Polymeric Materials: A Review
}

\author{
${ }^{1,2}$ Rolando Pedicini \\ ${ }^{1}$ Institute for Advanced Energy Technologies, Via S. Lucia Sopra Contesse 5, 98126-Messina, Italy \\ ${ }^{2}$ Affiliated to Dipartimento di Fisica, Universitàdella Calabria, \\ Via Ponte P. Bucci, Cubo 31C, 87036 Arcavacata di Rende (CS), Italy
}

Article history

Received: 04-07-2017

Revised: 06-07-2017

Accepted: 14-07-2017

E-mail: rolando.pedicini@itae.cnr.it
Abstract: Hydrogen storage is one of the major obstacles to overcoming so that hydrogen becomes next fuel and/or energy carrier of the future. The hydrogen storage materials are one of the principal challenges that must be met before the development of a hydrogen economy. Among all materials studied an important class that could have a future, in particular in portable applications, is the polymers class. Here are reported some results obtained using different polymeric matrices in different operative conditions.

Keywords: Review on Polymers, Chemical-Physical Characterizations, $\mathrm{H}_{2}$ Storage

\section{Introduction}

Hydrogen is presently considered as one of promising ecologically clean energy carriers for transport of the future. Therewith, the use of a combination of a hydrogen air fuel cell and electric engine, rather that substitution of fossil fuels in Internal Combustion Engines (ICEs) by hydrogen is considered to hold the greatest promise.

Hydrogen fuel cell produce energy with environmentally friendly burning byproducts; however, the low $\mathrm{H}_{2}$ density obliges that it can be stored in tank sat high pressure $(70 \mathrm{MPa})$ having specifics characteristics in terms of safety, system mass, volume and its cost.

The aim is to have a cheap material, easy to synthetized with good properties in terms of $\mathrm{H}_{2}$ sorption capability, comparable to $\mathrm{H}_{2}$ compressed (about $5 \mathrm{wt} \%$ ), at room conditions. As a consequence, the United States Department of Energy (US-DOE) and the United States Council for Automotive Research (US-CAR), promoted the first targets for the materials to be used in automotive application. These targets are changed successively, 2009, reducing the storage capacity until $5 \mathrm{wt} \%$ (FCHJU, 2014). Since in this field there is a lot number of materials that are used both in portable and stationary applications, it can be useful to consider them by two kind of mechanisms: (1) Hydrogen chemisorption; atomic hydrogen interacts with the material sites by chemical bonds. The most common materials belonging to this category are metal hydrides, complex hydrides and chemical hydrides. Their good capability to store $\mathrm{H}_{2}$ occurs, after activation steps, by using drastic condition of temperature and pressure. The main drawback of these materials is of thermodynamic nature. A lot papers are carried out to overcome these problems and to achieve fast reaction kinetics (Schüth et al., 2004). (2) Physisorption, molecular $\mathrm{H}_{2}$ interacts on the surface of the material with weak bonds, such as Van der Waals forces, that do not give any alteration in the material. In this class can be considered Metal-Organic Frameworks (MOFs) (Rowsell et al., 2004), nanoporous carbon (Ting et al., 2015), Carbon Nanotubes (CNTs) (Barghi et al., 2014).

The incorporation of nanoparticles or nanoporous structures in polymeric materials may be an alternative to obtain materials with promising properties for hydrogen storage. Different polymers are studied, including: Polyaniline (PANI) (Naresh et al., 2015), Polypyrrole (PPY) (Nour et al., 2014), polythiophene used as activation material for porous carbon (Sevilla et al., 2011), hyperbranchedpolyurea (P-Urea) (Rehim et al., 2011), hyperbranched Poly (Amide-Amine) (PAMAM), Polymer Dispersed Metal Hydrides (PDMH) (Schmidt, 2001). Another big class of polymers is represented by Microporous Poymers (Wood et al., 2007; Li et al., 2010).

Other interesting class is composed by composite polymers were metal oxide, such as Mn oxide, is synthesized in situ (Pedicini et al., 2011; 2014; 2017).

\section{Hydrogen Storage Measurements}

To know the real $\mathrm{H}_{2}$ storage capabilities of solid materials different methodology are used, among all, gravimetric and volumetric methods are more common. These characterizations give lot information not only in term of $\mathrm{H}_{2}$ sorption/desorption properties, but in 
addition, the energy and the thermodynamics aspect of the reactions. Each of these measurement methods has different characteristics; in this way to determine whether it is more suitable it is important to know what type of reaction occurs, chemisorption or physisorption. Gravimetric method is a direct way to know $\mathrm{H}_{2}$ storage capacity as the final result gives a $\mathrm{H}_{2}$ $\%$ of sorption. On the contrary, a drawback of this apparatus is determined at the start of the measurement in which the Buoyancy effect can condition the final value. Volumetric measurement is a indirect method were the $\mathrm{H}_{2}$ wt $\%$ it is possible calculate knowing the volume, $\mathrm{H}_{2}$ moles and pressure value. The main drawback of this technic is the $\mathrm{H}_{2}$ leak can be occur during the measure; this no real value could be considered as $\mathrm{H}_{2}$ adsorption.

\section{Volumetric Method}

This method, named Sievert apparatus also, gives the $\mathrm{H}_{2}$ storage value through temperature-pressurevolume correction. As before described, this kind of measure is an indirect method so volumes and temperatures of tank and sample must be known in advance. A thermocouple is located close to sample holder and the $\mathrm{T}$ must maintain constant during the measure; the calibrate volume must be chosen carefully. The pressures of the tank and the sample holder can be measured using pressure transducers.

Normally, $\mathrm{H}_{2}$ tank is set at a specific pressure (measurement pressure) and, after some minute that it is necessary to reach the thermic equilibrium, it can be recorded the $\mathrm{H}_{2}$ storage value (Blach et al., 2007; Webb et al., 2013).

\section{Gravimetric Method}

This methodology uses a microbalance to know in real time the changing of the sample mass during the measurement. Generally, before the test, it must be known the sample mass, in this way it is possible, by the difference of two values, the real percentage of $\mathrm{H}_{2}$ adsorbed. The sample holder is designed to minimize the Buoyancy effect, that can give and important error in the first step of the measurement. The chamber containing the sample holder is filled with hydrogen at a certain pressure, with a temperature and volume known. During the measurements, if there is a sorption of gas there will be an increase in sample mass and a decrease of pressure (Ansòn et al., 2004).

\section{Comparison Results}

One of the most widely used materials in hydrogen storage is the Polyaniline (PANI). Some years ago first studies was carried out on treated PANI and PPY. The authors confirm that the HCL treatment for both polymer promote the $\mathrm{H}_{2}$ sorption properties, in fact, they report an $\mathrm{H}_{2}$ storage value in a range of $6-8 \mathrm{wt} \%$ at $298 \mathrm{~K}$ and 90 bar (Cho et al., 2002). This result, although the same materials and the same procedure have been used, the same results have never been achieved (Panella et al., 2005).

The possible explanation of this increased $\mathrm{H}_{2}$ sorption capacity was in the formation of microporous in the structure after the acid treatment (Deb et al., 2007). This possible PANI characteristic has increased the interest of the researcher for this polymer; so, PANI having different morphology such as Fibers and NanoFibers (PANI-NF) had produced several interesting results with very easy synthesis and controlled porous (Long et al., 2011).

Some PANI-NF mixed to surfactant and sucrose were obtained. The hydrogen uptake using a surfactant, at 298 $\mathrm{K}$ and 80 bar, was about $3 \mathrm{wt} \%$ (Jurczyk et al., 2009). A higher value, at room temperature and 20 bar, than previous sample was obtained using sucrose in the synthesis; this kind of materials adsorbed 4,3 wt $\%$ of $\mathrm{H}_{2}$ (Rahy et al., 2011).

Another approach, using PANI as a matrix, was utilising different nanomaterials having different characteristics. These nanofillers, thought as catalysts, can be improve the $\mathrm{H}_{2}$ storage properties of the modified PANI. Some of these, such as MWNTs, $\mathrm{SnO}_{2}$ and $\mathrm{Al}$ powder, were found interesting $\mathrm{H}_{2}$ storage value in a T range of 298-398 K. In fact PANI with Al powder at 398 $\mathrm{K}$ improve the $\mathrm{H}_{2}$ sorption of pristine PANI from 0,35 to $0,5 \mathrm{wt} \%$ at 60 bar (Jurczyk et al., 2007).

This kind of materials, due to their good adsorption kinetic reaction, better than metal hydrides, have obtained very attention, in particular in the last years (Germain et al., 2009). The modified PANI, utilising different cross-linking agent, showed a high surface area reaching a value up to $632 \mathrm{~m}^{2} \mathrm{~g}^{\square 1}$.

The hydrogen storage values, operating at $77 \mathrm{~K}$ and 60 bar, were about 2,5 wt\% (Germain et al., 2007).

Another kind of polymer, Polythiophene activated with $\mathrm{KOH}$ solution, produces porous carbons having a surface area up to $3000 \mathrm{~m}^{2} \mathrm{~g}^{-1}$ (Sevilla et al., 2011). A very high hydrogen storage value, 5,71 wt $\%$, was found at $77 \mathrm{~K}$ and 20 bar, while at 1 bar hydrogen uptake decreases at 2,33 $\mathrm{wt} \%$.

Hyperbranched Polyurea (P-Urea) was characterized in cryogenic condition up to 20 bar. These isotherm test reveala linear correlation between the hydrogen storage percentage and the pressure test, in-fact, the trends shows at $5 \mathrm{bar}, 0,3 \mathrm{wt} \%$ of $\mathrm{H}_{2}$ sorption, increasing the pressure at 15 bar its $\mathrm{H}_{2}$ storage capability increases until $1 \mathrm{wt} \%$. At the end of the test, over than $20 \mathrm{bar}$, it stores about 1,4 wt $\%$.

Pure Hyperbranched poly (amide-amine) (PAMAM) and PAMAM composite with Vanadium Oxide $\left(\mathrm{VO}_{\mathrm{x}}\right)$ were studied in cryogenic conditions. Pure PAMAM is able to adsorbs $0,9 \mathrm{wt} \%$ at 25 bar while pure $\mathrm{VO}_{\mathrm{x}}$ adsorbs about $0,6 \mathrm{wt} \%$ at 20 bar. Both $\mathrm{H}_{2}$ adsorption trend are linear thus, their $\mathrm{H}_{2}$ storage capacity have a direct proportionality. 
To increase the $\mathrm{H}_{2}$ storage capacity of PAMAM, $\mathrm{VO}_{\mathrm{x}}$ was incorporate in the polymeric matrix to develop PAMAM/ $\mathrm{VO}_{\mathrm{x}}$ nanocomposite. A new composite material shows an increase of $\mathrm{H}_{2}$ sorption reaching 2 wt $\%$ under the same measuring conditions ( 25 bar). Due to a layered structure, $\mathrm{VO}_{\mathrm{x}}$ should increase the interlayer distance leading a more high hydrogen uptake.

Other interesting classes of materials are Polymer Dispersed Metal Hydrides (PDMH). The aim is to disperse metal hydrides in a particular polymeric matrix with a final product having a high $\mathrm{H}_{2}$ storage capacity, due to metal alloy presence and low density since polymeric matrix gives this properties to the hybrid material. The dispersion of the metal hydride in a polymeric matrix gives an increase of the metal alloy stability, in particular during $\mathrm{H}_{2}$ charge/discharge cycles; in addition, a possible little quantity of hydrogen could be stored in the polymeric layers.

Polymers with Intrinsic Micro porosity (PIMs) having lately very importance due to their important morphological characteristics.

PIMs are amorphous organic micro porous materials that have the pores size less than $2 \mathrm{~nm}$ diameter. PIM micro porosity derives from the fused ring structures, which prevent free rotation along the polymer backbone, resulting in a highly rigid and contorted fixed shape. Therefore, the final product will have a several number of free volumes, as a consequence of a surface area up to $2000 \mathrm{~m}^{2} \mathrm{~g} \square$. PIMs couple the advantages of polymers with the advantages of conventional micro porous materials. In this kind of materials there is a direct correlation between surface area and hydrogen storage capability. Considering, for example, a PIM obtained by mixing Catechol and Aryl alide, has a surface area ranging between $760-850 \mathrm{~m}^{2} \mathrm{~g}^{\square 1}$ with a $\mathrm{H}_{2}$ sorption capacity of about $1 \mathrm{wt} \%$ at $77 \mathrm{~K}$ and 1 bar. Another network polymer demonstrating a large surface area of $960 \mathrm{~m}^{2} \mathrm{~g}^{\square 1}$ is composed by Porphyrin and PIM. This kind of material shows a more high surface area, of about $960 \mathrm{~m}^{2} \mathrm{~g} \square$, adsorbing $1,9 \mathrm{wt} \%$ of $\mathrm{H}_{2}$ in the same measurement conditions. A very high surface area of a mixed PIM with Tripticene was found, about $1159 \mathrm{~m}^{2}$ $\mathrm{g}^{\square 1}$, the relative $\mathrm{H} 2$ sorption test, at $77 \mathrm{~K}$ and 1 bar reveal a $\mathrm{H}_{2}$ sorption value of $1,83 \mathrm{wt} \%$ that increases until $3,2 \mathrm{wt} \%$ at $10 \mathrm{bar}$.

Another innovative class of hydrogen storage materials consists of composites polymer using a metal oxide (Manganese Oxide) as adsorbent material anchored to a polymeric matrix (Polyetheretherketone, PEEK). Functionalised PEEK, using Chlorosulfonic acid, shows a higher sulphonation degree (over that 100\%) (Pedicini et al., 2011). Manganese oxide was inserted using a Mn precursor such as $\mathrm{KMnO}_{4}$ solution at different concentration (from $0,02 \mathrm{M}$ to $0,1 \mathrm{M}$ ). This reaction can occurs changing the experimental parameters as temperature and time of reaction. In this way, different $\mathrm{Mn}$ oxide content was obtained (starting from $15 \mathrm{wt} \%$ until $82 \mathrm{wt} \%$ ). XRD analyses reveal the anchorage of the oxide with a probable crystalline structure based on Birnessite (lamellar structure). This kind of oxide, confirmed XPS analyses, was $\mathrm{MnO}_{2} \cdot \mathrm{H}_{2}$ sorption measurements in cryogenic conditions showed interesting values of sorption: $1,1 \mathrm{wt} \%$ at $1 \mathrm{bar}$ after different $\mathrm{H}_{2}$ sorption desorption tests Fig. 1 .

More high $\mathrm{H}_{2}$ storage values were obtained in a $\mathrm{T}$ range between 323-383 K using Sievert apparatus. As reported in Table 1, increasing $\mathrm{MnO}_{2}$ content increases the $\mathrm{H}_{2}$ storage capacity. It was found that the $\mathrm{T}$ of the synthesis cannot overcome $323 \mathrm{~K}$ since, a more drastic condition, an irreversible $\mathrm{H}_{2}$ sorption trend was recorded (Wood et al., 2007) (15).

Limiting the $\mathrm{T}$ of the synthesis at $323 \mathrm{~K}$ and testing these samples in the same $\mathrm{T}$ condition were obtained very promising results, as reported in Fig. $2 \mathrm{a}$ and $2 \mathrm{~b}$.

The final $\mathrm{H}_{2}$ sorption value obtained was about 3,5 $\mathrm{wt} \%$, even if the kinetic reaction was very slow. The reversibility was verified by $\mathrm{H}_{2}$ sorption/desorption cycles Fig. $2 b$ in which a very short time it is necessary to desorb $\mathrm{H}_{2}$.

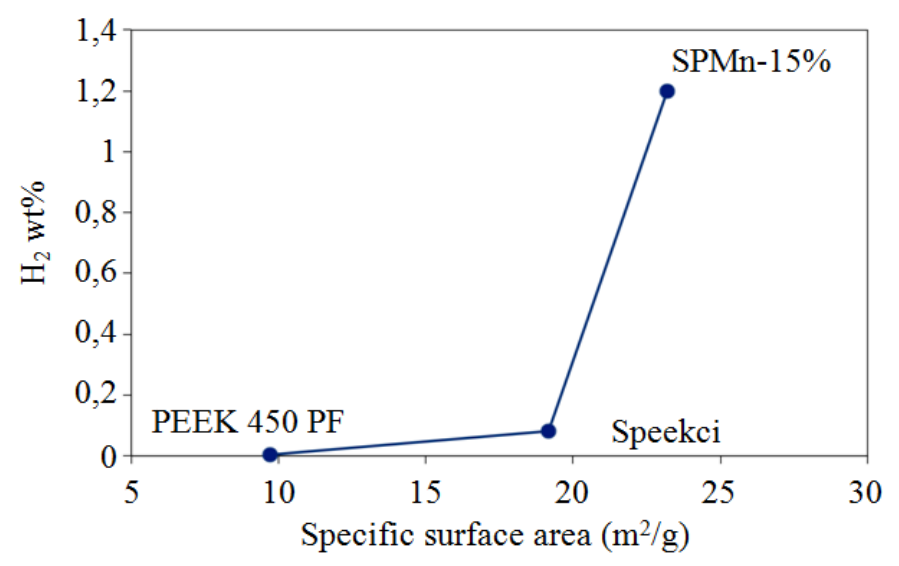

Fig. $1 . \mathrm{H}_{2}$ sorption trend at $77 \mathrm{~K} / 1$ bar 


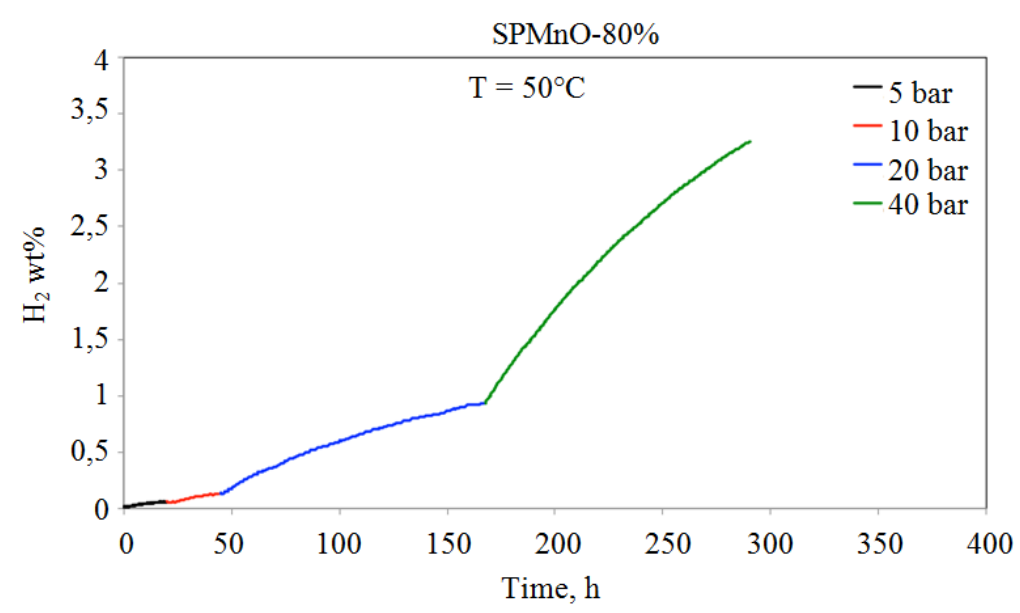

(a)

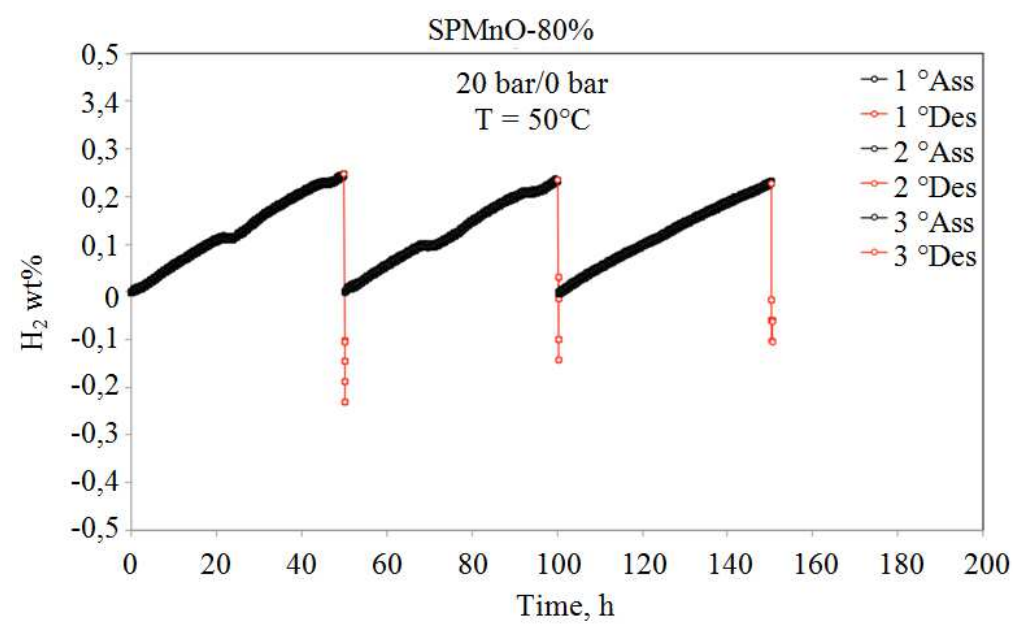

(b)

Fig. 2. (a) $\mathrm{H}_{2}$ sorption test and (b) short $\mathrm{H}_{2}$ sorption/desorption test. It reproduced with permission of Elsevier

Table $1 . \mathrm{H}_{2}$ sorption values of synthetized materials

\begin{tabular}{llll}
\hline $\mathrm{MnO}_{2} \mathrm{wt} \%$ & $\mathrm{~T} / \mathrm{K}$ & $\mathrm{P} /$ bar & $\mathrm{H}_{2} \mathrm{wt} \%$ \\
\hline 15 & 383 & 40 & 0,1 \\
20 & 383 & 60 & 0,2 \\
78 & 383 & 60 & 1,2 \\
80 & 323 & 40 & 3 \\
\hline
\end{tabular}

\section{Conclusion}

The hydrogen storage properties of some materials based on polymeric matrix were discussed. In these last years, this kind of materials have been mostly studied since they have interesting characteristics to promote a fuel cell portable applications and, consequently, the $\mathrm{H}_{2}$ use as a fuel. A lot of papers focus their effort considering common polymers such as PANI, PIM, PEEK etc., modifying their morphology and/or structure mixing them with metals, metal oxides or other porous polymers. The mainly of the polymeric materials have the best $\mathrm{H}_{2}$ storage performances in cryogenic conditions. Lately, these new classes of functionalized polymer act over than room temperature in not drastic condition in term of $\mathrm{P}$. The aim, as well as other types of materials, is to be able to approach the DOE targets, over than $5 \mathrm{wt} \%$ of $\mathrm{H}_{2}$ sorption.

\section{Ethics}

This article is original and contains unpublished material. The corresponding author confirms that all of the other authors have read and approved the manuscript and there are no ethical issues involved.

\section{Conflict of interest}

The author declare that have no conflict of interest.

\section{References}

FCHJU, 2014. Fuel cells and hydrogen joint undertaking. Annual Work Plan. 
Ansòn, A., M. Benham, J. Jagiello, M.A. Callejas and A.M. Benito et al., 2004. Hydrogen adsorption on a single-walled carbon nanotube material: A comparative study of three different adsorption techniques. Nanotechnology, 15: 1503-1508.

Barghi, S.H., T.T. Tsotsis and M. Sahimi, 2014. Chemisorption, physisorption and hysteresis during hydrogen storage in carbon nanotubes. Int. J. Hydrogen Energy, 39: 1390-1397

Blach, T.P., E. Mac and A. Gray, 2007. Sieverts apparatus and methodology for accurate determination of hydrogen uptake by light-atom hosts. J. Alloys Compounds, 446-447: 692-697.

Cho, S.J., K.S. Song, J.W. Kim, T.H. Kim and K. Choo, 2002. Hydrogen sorption in HCl-treated polyaniline and polypyrrole; new potential hydrogen storage media. Fuel Chem. Division Preprints, 47: 790-790.

Deb, P.C., L.D. Rajput and P.K. Singh, 2007. Polyaniline encapsulated microporous polymer beads and their vapor and gas adsorption behavior. J. Applied Polymer Sci., 104: 297-303.

Germain, J., J.M.J. Frèchet and F. Svec, 2007. Hypercrosslinked polyanilines with nanoporous structure and high surface area: potential adsorbents for hydrogen storage. J. Mater. Chem., 17: 4989-4989.

Germain, J., J.M.J. Frèchet and F. Svec, 2009. Nanoporous polymers for hydrogen storage. Small, 5: 1098-1098.

Jurczyk, M.U., A. Kumar, S.S. Srinivasan and E.K. Stefanakos, 2007. Polyaniline-based nanocomposite materials for hydrogen storage. Int. J. Hydrogen Energy, 32: 1010-1010.

Jurczyk, M.U., S.S. Srinivasan, A.R. Phani, A. Kumar and D.Y. Goswami et al., 2009. Room Temperature Reversible Hydrogen Storage in Polyaniline (PANI) Nanofibers. J. Nanosci. Nanotechnol., 9: 4561-4561.

Li, B., X. Huang, L. Liang and T. Bien, 2010. Synthesis of uniform microporous polymer nanoparticles and their applications for hydrogenstorage. J. Mater. Chem., 20: 7444-7450.

Long, Y.Z., M.M. Li, C. Gub, M. Wanc and J.L. Duvail et al., 2011. Recent advances in synthesis, physical properties and applications of conducting polymer nanotubes and nanofibers. Progress Polymer Sci., 36: 1415-1415.

Naresh, M.R., S. Rajashabala and R. Kannan, 2015. Synthesis and characterization of polymer (sulfonated poly-ether-ether-ketone) based nanocomposite (hboron nitride) membrane for hydrogen storage. Int. J. Hydrogen Energy, 40: 1836-1845.

Nour, F.A., S.M. Lee, H.J. Kim and K.E. Geckele, 2014. Nanoporous polypyrrole: Preparation and hydrogen storage properties. Int. J. Energy Res., 38: 466-476.
Panella, B., L. Kossykh, U. Dettlaff-Weglikowsa, M. Hirscher and G. Zerbi et al., 2005. Volumetric measurement of hydrogen storage in $\mathrm{HCl}$-treated polyaniline and polypyrrole. Synthetic Metals, 151: 208-221.

Pedicini, R., A. Saccà, A. Carbone and E. Passalacqua, 2011. Hydrogen storage based on polymeric material. Int. J. Hydrogen Energy, 36: 9062-9068.

Pedicini, R., B. Schiavo, P. Rispoli, A. Saccà and A. Carbone et al., 2014. Progress in polymeric material for hydrogen storage application in middle conditions. Energy, 64: 607-614.

Pedicini, R., M. Sigalas, A. Carbone and I. Gatto, 2017. Functionalised hybrid poly (ether ether ketone) containing $\mathrm{MnO}_{2}$ : Investigation of operative conditions for hydrogen sorption. Int. J. Hydrogen Energy, 42: 10089-10098.

Rahy, A., T. Rguig, S.J. Cho, C.E. Bunker and D.J. Yang, 2011. Polar solvent soluble and hydrogen absorbing polyaniline nanofibers. Synthetic Metals., 161: 280-280.

Rehim, M.H.A., N. Ismail, A.A. Abd El-Rahman and G.T. Badawyb, 2011. Hydrogen storing and electrical properties of hyperbranched polymersbased nanoporous materials. Mater. Sci. Eng. B, 176: 1184-1189.

Rowsell, J.L.C., A.R. Millward, K.S. Park and O.M. Yaghi, 2004. Hydrogen sorption in functionalized metal-organic frameworks. J. Am. Chem. Society, 126: 5666-5667.

Schmidt, W.R., 2001. Proceedings of the DOE hydrogen program review.

Schüth, F., B. Bogdanović and M. Felderhoff, 2004. Light metal hydrides and complex hydrides for hydrogen storage. Chem. Commun.

Sevilla, M., A.B. Fuertes and R. Mokaya, 2011. Preparation and hydrogen storage capacity of highly porous activated carbon materials derived from polythiophen. Int. J. Hydrogen Energy, 36: 15658-15663.

Ting, V.P., A.J. Ramirez-Cuesta, N. Bimbo, J.E. Sharpe and A. Noguera-Diaz et al., 2015. Direct evidence for solid-like hydrogen in a nanoporous carbon hydrogen storage material at supercritical temperatures. Am. Chem. Society Nano., 9: 8249-8254

Webb, C.J., E. Mac and A. Gray, 2013. Misconceptions in the application of the sieverts technique. Int. J. Hydrogen Energy, 38: 14281-14283.

Wood, C.D., B. Tan, A. Trewin, H. Niu and D. Bradshaw et al., 2007. Hydrogen storage in microporous hypercrosslinked organic polymer networks. Chem. Mater., 19: 2034-2048.a 